Article

\title{
Formulation of New Media from Dairy and Brewery Wastes for a Sustainable Production of DHA-Rich Oil by Aurantiochytrium mangrovei
}

\author{
Giovanni L. Russo ${ }^{1, *(\mathbb{D})}$, Antonio L. Langellotti ${ }^{2}$ (D), Vito Verardo ${ }^{3,4}\left(\mathbb{D}\right.$, Beatriz Martín-García ${ }^{3,4}$, \\ Prospero Di Pierro ${ }^{1,2} \mathbb{D}$, Angela Sorrentino ${ }^{2}$, Marco Baselice ${ }^{2}$, Maria Oliviero ${ }^{2}$, Raffaele Sacchi ${ }^{1}$ (D) \\ and Paolo Masi 1,2
}

Citation: Russo, G.L.;

Langellotti, A.L.; Verardo, V.;

Martín-García, B.; Di Pierro, P.;

Sorrentino, A.; Baselice, M.;

Oliviero, M.; Sacchi, R.; Masi, P.

Formulation of New Media from

Dairy and Brewery Wastes for a

Sustainable Production of DHA-Rich

Oil by Aurantiochytrium mangrovei.

Mar. Drugs 2022, 20, 39. https://

doi.org/10.3390/md20010039

Academic Editor: Vasily Svetashev

Received: 30 November 2021

Accepted: 28 December 2021

Published: 29 December 2021

Publisher's Note: MDPI stays neutral with regard to jurisdictional claims in published maps and institutional affiliations.

Copyright: (C) 2021 by the authors. Licensee MDPI, Basel, Switzerland. This article is an open access article distributed under the terms and conditions of the Creative Commons Attribution (CC BY) license (https:// creativecommons.org/licenses/by/ $4.0 /)$.
1 Unit of Food Science and Technology, Department of Agricultural Sciences, University of Naples Federico II, 80055 Portici, Italy; prospero.dipierro@unina.it (P.D.P.); sacchi@unina.it (R.S.); masi@unina.it (P.M.)

2 CAISIAL Center, University of Naples Federico II, Via Università 133, 80055 Portici, Italy; langello@unina.it (A.L.L.); angela.sorrentino@unina.it (A.S.); marco.baselice@unina.it (M.B.); maria.oliviero2@unina.it (M.O.)

3 Department of Nutrition and Food Science, Campus of Cartuja, University of Granada, 18071 Granada, Spain; vitoverardo@ugr.es (V.V.); bea91mg@ugr.es (B.M.-G.)

4 Biomedical Research Center, Institute of Nutrition and Food Technology 'José Mataix', University of Granada, Avda del Conocimiento sn., 18100 Armilla, Spain

* Correspondence: giovanniluca.russo@unina.it; Tel.: +39-0812539005

\begin{abstract}
Mozzarella stretching water (MSW) is a dairy effluent generated from mozzarella cheese production that does not have a real use and is destined to disposal, causing environmental problems and representing a high disposal cost for dairy producers. Spent brewery yeast (SBY) is another promising food waste produced after brewery manufacturing that could be recycled in new biotechnological processes. Aurantiochytrium mangrovei is an aquatic protist known as producer of bioactive lipids such as omega 3 long chain polyunsaturated fatty acids ( $\omega 3$ LC-PUFA), in particular docosahexaenoic acid (DHA). In this work MSW and SBY have been used to formulate new sustainable growth media for $A$. mangrovei cultivation and production of DHA in an attempt to valorize these effluents. MSW required an enzymatic hydrolysis to enhance the biomass production. The new media obtained from hydrolysed MSW was also optimized using response surface methodologies, obtaining $10.14 \mathrm{~g} \mathrm{~L}^{-1}$ of biomass in optimized medium, with a DHA content of $1.21 \mathrm{~g} \mathrm{~L}^{-1}$.
\end{abstract}

Keywords: microalgae; food waste; PUFA; DHA; bioconversion; sustainability; carotenoids

\section{Introduction}

Long chain $\omega-3$ polyunsaturated fatty acids (LC-PUFA) have a series of beneficial effects on human health [1]. Among them, docosahexaenoic acid (DHA, C22:6n-3) is an important fatty acid, as it is one of the major components of the central nervous system [2]. Moreover, dietary DHA supplementation has been shown to be important in the prevention of cardiovascular diseases, schizophrenia, and specific types of cancer [3].

Actually, the principal source of DHA is fish oil, but it has several disadvantages, especially the low sustainability, the contamination by marine pollutants, fish allergy issues and an undesirable fishy smell $[4,5]$. Thraustochytrids, a heterotrophic funguslike clade of Stramenopiles, represent a potential alternative to fish oil due to their high biomass and DHA productivity, which is much higher than the fish source [6]. Among the thraustochytrids, Aurantiochytrium (known as Schizochytrium until 2007) is a genus industrially exploited for the production of DHA [7]. Aurantiochytrium can produce high amounts of lipids (up to 55\% of dry weight) and most of that is DHA (up to $35 \%$ of total fatty acids) [7]. For the industrial production of DHA, the price of growth medium represents a significant portion of the production costs, as well as the costs for preparing artificial sea 
water [8]. For that reason, new biotechnological processes based on the recycling of low cost side-streams from food industries would be an interesting way to produce omega-3 oil with lower production costs. The utilization of aquatic protists for treatment of food waste is gaining attention from the scientific community, thanks to their great metabolic flexibility and bioremediation capacities [9]. Aurantiochytrium sp. has been tested on different types of food waste, showing a high metabolic versatility to utilizing different type of organic and nitrogen sources $[10,11]$.

The dairy industry is one of the main food industries in Italy and Europe, with tons of cheese produced every year. In Italy the main dairy product is the mozzarella cheese, with a production of more than 250,000 tons every year [12]. During the mozzarella manufacturing process, two main side-streams are generated: the cheese whey $(\mathrm{CW})$ and the mozzarella stretching water (MSW). MSW is the effluent generated after the stretching step. It is treated as an effluent by the dairy companies because of its high salinity and high chemical oxygen demand (COD), and therefore it represents a serious environmental issue [13]. Nevertheless, dairy wastewaters are liquids rich in interesting compounds such as lactose (up to $5 \% w / v$ ), proteins (up to $1 \% w / v$ ), and other minor components (mineral salts, lactic acid and vitamins). Dairy by-products could be useful for the formulation of more sustainable microbial media [14], in particular for heterotrophic microorganisms that require high amounts of organic carbon and other nutrients for their growth.

Another promising food waste for biotechnological applications is the spent brewery yeast (SBY). It is an organic waste from brew manufacturing with a high content of proteins, free amino nitrogen (FAN), phosphates and other essential mineral salts [11]. These characteristics make this food waste very promising for microalgal cultivation [15]. In fact, SBY could be used in the formulation of a new medium obtained mainly from food wastes.

To the best of our knowledge, Aurantiochytrium cultivation was never tried on dairy wastewater. We found only one paper about testing the saline wastewater from demineralization of CW for the cultivation of Schizochytrium limacinum PA-968 [8].

Therefore, the purpose of this study was to investigate the potential of a dairy wastewater (MSW) in combination with SBY as a new sustainable growth medium for Aurantiochytrium mangrovei cultivation. The chemical characteristics of MSW have been defined, and the new media optimized through response surface analysis with supplementation of nitrogen from brewery waste. The biochemical composition and lipid content of the obtained biomass have also been determined.

\section{Results and Discussion}

\subsection{Characterization of MSW}

The chemical and physical characterizations of reverse osmosis concentrated MSW (3:1) are reported in Table 1.

The chemical composition of MSW is not well defined in scientific literature. This wastewater is interesting for the amount of reducing sugars (up to $23 \mathrm{~g} \mathrm{~L}^{-1}$ ), and also for a residual content of proteins $\left(3.6 \mathrm{~g} \mathrm{~L}^{-1}\right)$. The content of free amino nitrogen (FAN) is also relevant $\left(0.174 \mathrm{mg} \mathrm{L}^{-1}\right)$, as it is easily metabolized by aquatic protists, boosting their growth [16].

Moreover, the high amount of ash and chlorides make this waste a candidate for fermentation by marine microorganisms (i.e., Aurantiochytrium mangrovei). In fact, a high saline content is a common characteristic for this type of dairy effluent. The phosphorus (P) content reported was $87 \mathrm{mg} \mathrm{L}^{-1}$, which is a good amount for protist cultivation because it is an essential macronutrient for energy transfer and synthesis of phospholipids and nucleic acids [17]. Considering that the P content of standard YEP medium is estimated to be $70-90 \mathrm{mg} \mathrm{L}^{-1}$, the MSW alone can satisfy the $\mathrm{P}$ demand of $A$. mangrovei. Magnesium and calcium reported were high if compared to standard medium. However, this amount of $\mathrm{Mg}^{2+}$ could positively affect the cultivation, because magnesium ions act as a cofactor for malic enzyme, which converts malic acid to pyruvate during the transdehydrogenase cycle [18]. 
Table 1. Chemical and physical characterization of mozzarella stretching water.

\begin{tabular}{|c|c|}
\hline Parameters & Value \\
\hline $\mathrm{pH}$ & $3.55 \pm 0.2$ \\
\hline $\operatorname{Ash}\left(\mathrm{g} \mathrm{L}^{-1}\right)$ & $26.2 \pm 0.9$ \\
\hline Dry weight $\left(\mathrm{g} \mathrm{L}^{-1}\right)$ & $68.5 \pm 1.1$ \\
\hline $\mathrm{N}$ total $\left(\mathrm{g} \mathrm{L}^{-1}\right)$ & $0.91 \pm 0.09$ \\
\hline Protein content $\left(\mathrm{g} \mathrm{L}^{-1}\right)$ & $3.6 \pm 0.2$ \\
\hline Lactic acid $\left(\mathrm{g} \mathrm{L}^{-1}\right)$ & $6.08 \pm 0.79$ \\
\hline Citric acid $\left(\mathrm{g} \mathrm{L}^{-1}\right)$ & $1.03 \pm 0.19$ \\
\hline Free amino nitrogen $\left(\mathrm{mg} \mathrm{L}^{-1}\right)$ & $0.174 \pm 0.03$ \\
\hline Reducing sugars (g L ${ }^{-1}$ ) & $23.26 \pm 0.4$ \\
\hline Lactose $\left(\mathrm{g} \mathrm{L}^{-1}\right)$ & $22.48 \pm 0.7$ \\
\hline Total sugars $\left(\mathrm{g} \mathrm{L}^{-1}\right)$ & $24.12 \pm 0.6$ \\
\hline $\operatorname{COD}\left(\mathrm{mg} \mathrm{L}^{-1}\right)$ & $33506 \pm 21.1$ \\
\hline $\mathrm{Cl}^{-}\left(\mathrm{g} \mathrm{L}^{-1}\right)$ & $14.61 \pm 1$ \\
\hline $\mathrm{Ca}^{2+}\left(\mathrm{g} \mathrm{L}^{-1}\right)$ & $0.69 \pm 0.05$ \\
\hline Total P (mg L $\left.{ }^{-1}\right)$ & $87.3 \pm 1.25$ \\
\hline $\mathrm{Na}^{2+}\left(\mathrm{g} \mathrm{L}^{-1}\right)$ & $7.66 \pm 0.8$ \\
\hline $\mathrm{Mg}^{2+}\left(\mathrm{mg} \mathrm{L}^{-1}\right)$ & $95.76 \pm 3.7$ \\
\hline
\end{tabular}

Values expressed as mean $(n=3) \pm$ SD.

MSW showed a low $\mathrm{pH}$ value (3.55), probably due to the presence of citric and lactic acid. The latter is produced after natural microbial fermentations of the stretching water by lactic acid bacteria (LAB) or other species of the present microbiota [19]. The presence of organic acids could be interesting for heterotrophic or mixotrophic cultivation of microorganisms. These factors contribute to the high organic load that characterizes the dairy effluents; in fact, the COD found was more than $33 \mathrm{~g} \mathrm{~L}^{-1}$, which is economically critical for producers that need to dispose of this type of wastewater.

Comparing these results with other dairy wastewater characterizations, we found that MSW has a lower $\mathrm{pH}$ value (3.5 vs. 4.7-5.1), a higher content of total nitrogen (TN) (900 mg/L vs. $140-800 \mathrm{mg} / \mathrm{L})$ and a lower amount of reducing sugars $(23.1 \mathrm{~g} / \mathrm{L}$ vs. $30-47 \mathrm{~g} / \mathrm{L})$ [20-22].

Nevertheless, the characteristics of MSW showed a promising nutrient composition for fermentations by marine protists. However, the amount of nitrogen and organic carbon are lower with respect to the standard YEP medium used for $A$. mangrovei cultivation.

\subsection{Screening Tests Results}

\subsubsection{Evaluation of Organic Carbon Sources}

The performance of $A$. mangrovei growth with different organic carbon sources is reported in Figure 1.

The protist showed a significant growth when using glucose, lactate and galactose as a source of organic carbon. This result is in line with other studies with the Aurantiochytrium species $[10,23,24]$. However, we found a significant difference $(p<0.05)$ between standard glucose, lactic acid and galactose. For lactose instead, no growth of $A$. mangrovei was observed after $72 \mathrm{~h}$, proving the impossibility to metabolize this disaccharide. In fact, in another work where Aurantiochytrium sp. was tested on a media supplemented with demineralized CW, the thraustochytrid showed significant growth only when supplemented with glycerol [8]. Lactate has been tested as it is produced in the dairy wastewater following fermentations by the microbiota. This organic acid can affect positively the fermentation by A. mangrovei. A previous study evaluated the growth of Schizochytrium sp. using lactic acid instead of glucose [25], and the authors reported that the biomass growth with lactic acid medium was lower than the glucose medium. These findings are in line with our work. For galactose also, our results are in line with another work conducted with Schizochytrium mangrovei Sk-02 [24]. The authors reported the capability to metabolize this monosaccharide, but with less efficiency than glucose. 


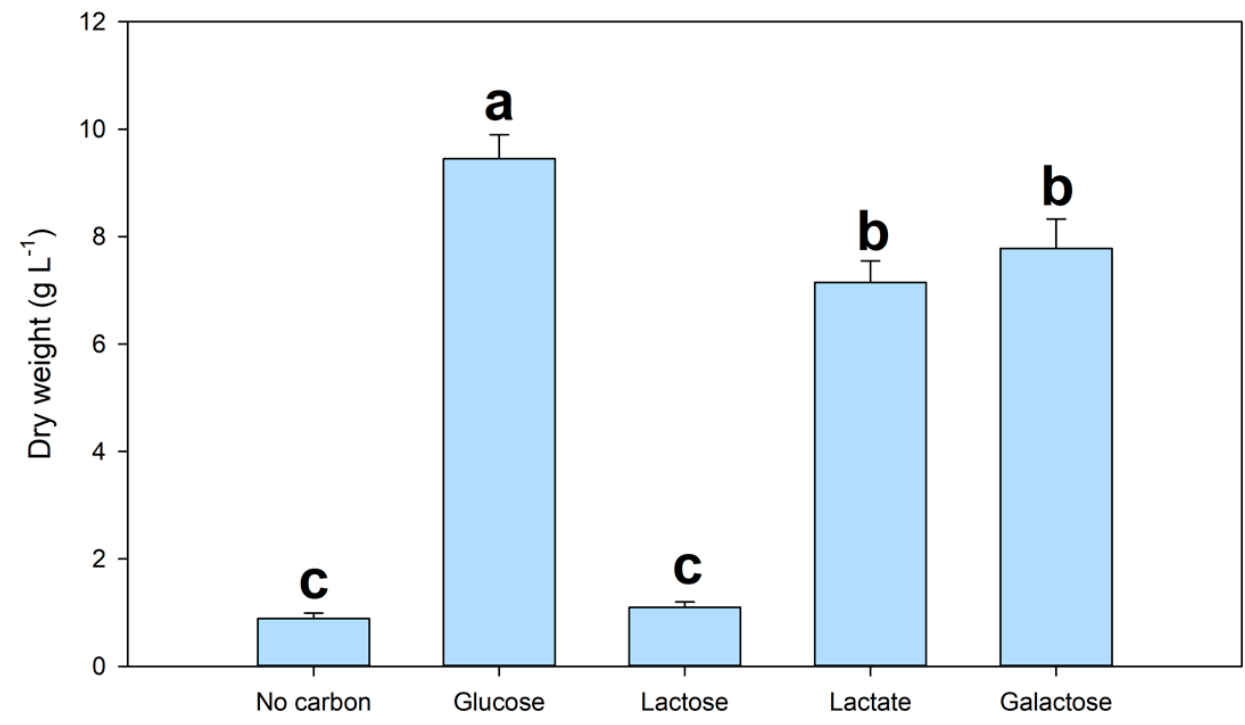

Figure 1. Screening test for different type of organic carbon source for A. mangrovei cultivation. The basal medium used for this test is yeast extract-peptone medium (YEP). Different letters mean a significant difference $(p<0.05)$ with $n=3$.

\subsubsection{Effect of MSW Hydrolysed and SBY on the Growth of A. mangrovei}

Since lactose is not metabolized by A. mangrovei (Figure 1) a hydrolysis of MSW was performed in order to increase the bioavailability of the nutrients present. The results of the first screening to evaluate the hydrolysis effect of MSW on A. mangrovei growth are reported in Figure 2A.

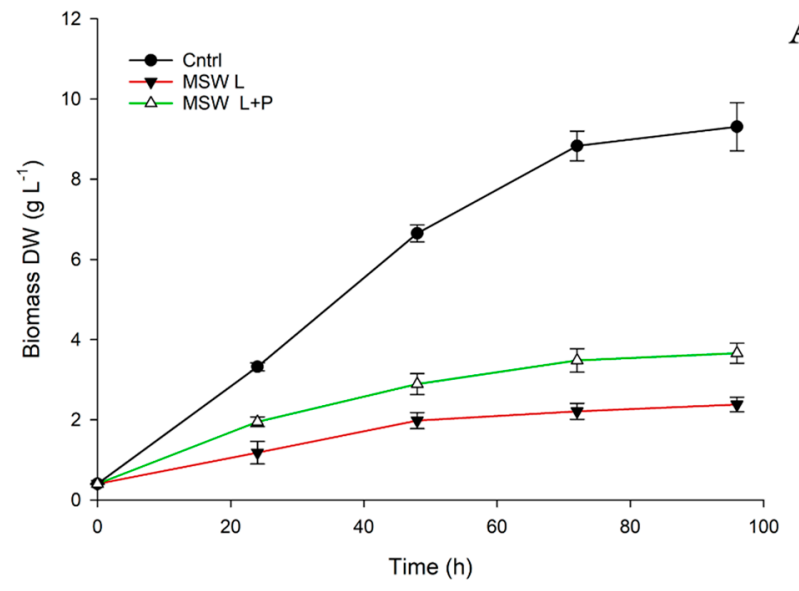

A

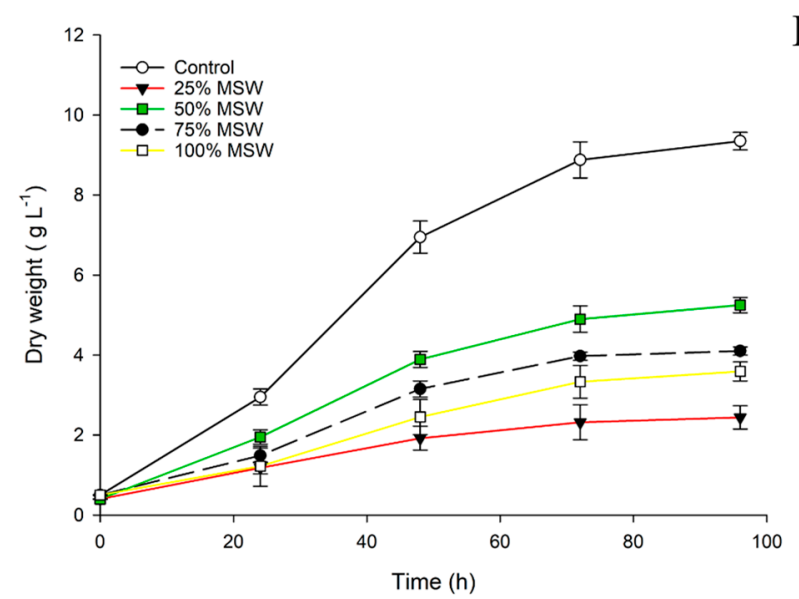

B

Figure 2. Evaluation of growth performance of $A$. mangrovei with MSW medium with only lactose hydrolysis (MSW L), with sequential lactose-protein hydrolysis (MSW L+P) (A) and screening of MSW hydrolyzed diluted at four different concentrations $(25-100 \% v / v)(\mathbf{B})$. All the tests were conducted in triplicate $(n=3)$. The controls refer to YEP standard medium.

When using a medium in which only lactose was hydrolysed (MSW L), a lower biomass was obtained with respect to the samples' growth with a medium subjected to sequential hydrolysis of proteins and lactose (MSW L+P). In fact, without the complete protein hydrolysis, a lower biomass growth can be observed in terms of dry cell weight (DW) (up to $2.2 \mathrm{~g} \mathrm{~L}^{-1}$ ) respect to the $3.63 \mathrm{~g} \mathrm{~L}^{-1}$ obtained on MSW L+P. After the sequential hydrolysis of MSW, the FAN content increased from $0.17 \mathrm{mg} \mathrm{L}^{-1}$ to $0.8 \mathrm{mg} \mathrm{L}^{-1}$, and this can explain the growth boost observed.

In fact, small peptides and FAN produced after proteolysis are used more efficiently by aquatic protists, enhancing their growth [9]. Also, the hydrolysis of lactose leads to glucose and galactose formation that can be easily metabolized by A. mangrovei (Figure 1a). 
In the work of Pleissner et al. [16], a "fungal" hydrolysis with A. awamori and A. oryzae was used to enhance the nutrient availability of food waste. The authors tested the growth of A. mangrovei (called Schizochytrium mangrovei), reporting a higher biomass productivity respect to the control, thanks to FAN and glucose released after fungal pre-treatment.

However, the overall growth observed in our screening was very poor with respect to the standard medium. For that reason, we evaluated also the concentration effect of hydrolyzed MSW (lactose and protein hydrolysis) on the biomass production. In Figure 2B are reported the growth curves at different concentrations of MSW.

As we expected, when using this dairy effluent integrally without dilution (at 100\% v/v of concentration), the growth performance was significantly lower than the control and $50 \%$ sample, obtaining only $2.1 \mathrm{~g} \mathrm{~L}^{-1}$ of DW after $96 \mathrm{~h}$ of cultivation. At $50 \%$ dilution instead, the growth was higher than the $100 \%$ and $75 \%$ samples, leading to $5.02 \mathrm{~g} \mathrm{~L}^{-1}$ of DW. This could be explained by a saline stress of the salts present in MSW or by other inhibitory substances present [26]. In fact, other authors reported a lower productivity when cultivating thraustochytrids at high salinity content $[27,28]$. Therefore, all the subsequent cultivation trials have been performed with hydrolyzed MSW diluted at $50 \%$ of concentration.

In our work, the ratio of the hydrolysis was the same, but the nutrients present in MSW were not sufficient to obtain a growth similar to the standard media (YEP medium). In fact, the nitrogen content of the standard medium was $0.95 \mathrm{~g} \mathrm{~L}^{-1}$ while the MSW diluted at $50 \%$ contains $0.46 \mathrm{~g} \mathrm{~L}^{-1}$ of $\mathrm{N}$. For that reason, we tested a waste from the brewery industry (SBY) as an alternative nitrogen source that could satisfy the nutritional demand of the microalga. The SBY screening test results are reported in Figure 3.

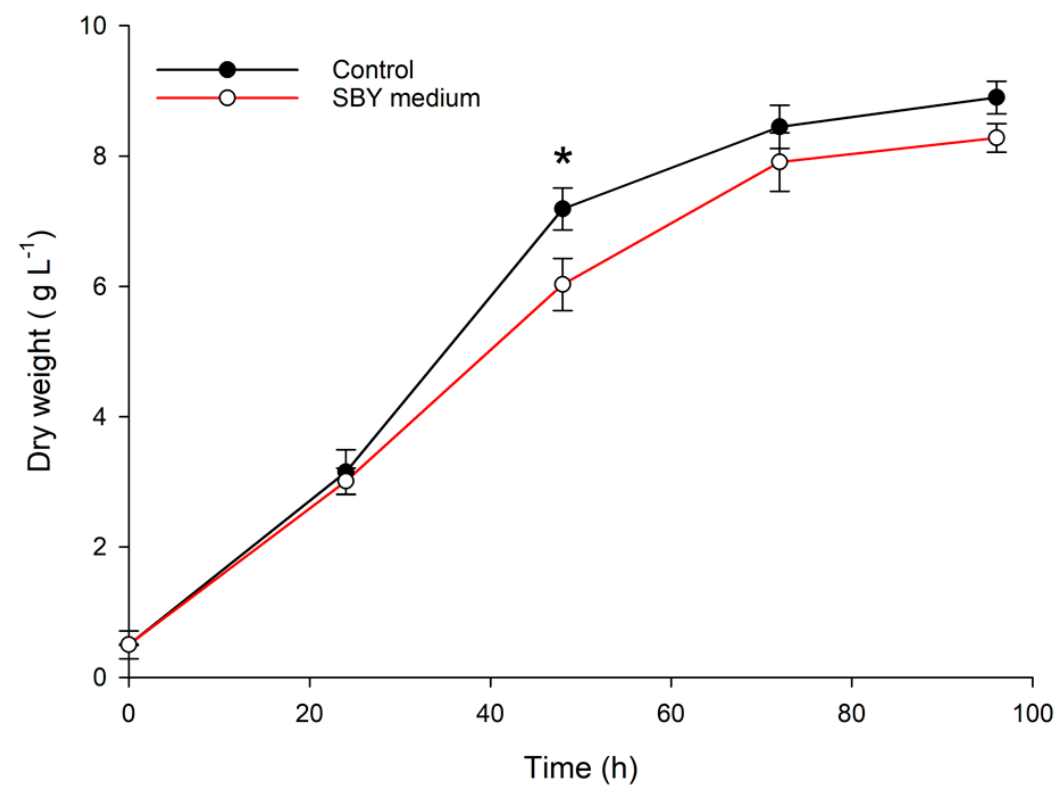

Figure 3. Growth curves of $A$. mangrovei cultivated with spent brewery yeast as the sole nitrogen source compared to standard medium. ${ }^{*}$ means a significant difference $(p<0.05)$ with $n=3$.

Substituting the nitrogen of standard media (from yeast extract and peptone) with nitrogen from SBY, no significant difference after $72 \mathrm{~h}$ and $96 \mathrm{~h}$ of cultivation was observed. A significant difference $(p=0.04)$ can be observed only at $48 \mathrm{~h}$ of cultivation, likely due to a slower uptake of nitrogen from SBY with respect to the standard YE. With this result, SBY could be used to compensate the lack of nitrogen of MSW medium.

This growth performance is in line with a previous work which obtained a biomass productivity $\left(\mathrm{g} \mathrm{L}^{-1}\right.$ day $^{-1}$ ) of $3.52 \pm 1.06$ by Aurantiochytrium sp. KRS101 when using SBY extracted after autolysis with distilled water as the only nitrogen source [11]. 


\subsection{Optimization of New MSW Hydrolysed Media}

In order to increase the biomass productivity, MSW medium required a nutrient supplementation. CCD was used to examine the optimal supplementation of organic carbon (glucose) and nitrogen (SBY) in the new MSW media. The response surface design employed gave 13 combinations of selected nutrients (glucose and SBY) with three levels $(-1$, $0,+1)$. Table 2 reports the design and the results with the responses. Biomass concentration (expressed as $\mathrm{g} \mathrm{L}^{-1}$ of DW) was used as response, and was calculated at log phase (72 h).

Table 2. Experiment design and results of biomass growth optimization with supplementation of glucose and SBY by central composite design.

\begin{tabular}{|c|c|c|c|c|}
\hline \multirow[b]{2}{*}{ Run } & \multicolumn{2}{|c|}{ Factor Assignment } & \multicolumn{2}{|c|}{ Biomass Dry Weight (Y) } \\
\hline & $\mathrm{X}_{1}$ (Glucose) & $X_{2}(\mathrm{SBY})$ & $\begin{array}{l}\text { Experimental Value } \\
\qquad\left(\mathrm{g} \mathrm{L} \mathrm{L}^{-1}\right)\end{array}$ & $\begin{array}{c}\text { Predicted Value } \\
\left(\mathrm{g} \mathrm{L}^{-1}\right)\end{array}$ \\
\hline 1 & -1 & 0 & 7.28 & 7.75 \\
\hline 2 & +1 & 0 & 10.24 & 10.06 \\
\hline 3 & +1 & +1 & 9.79 & 9.99 \\
\hline 4 & 0 & +1 & 9.87 & 9.73 \\
\hline 5 & 0 & 0 & 9.81 & 9.77 \\
\hline 6 & 0 & 0 & 9.72 & 9.77 \\
\hline 7 & +1 & -1 & 7.13 & 7.09 \\
\hline 8 & -1 & +1 & 7.85 & 7.73 \\
\hline 9 & 0 & 0 & 9.97 & 9.77 \\
\hline 10 & 0 & -1 & 6.38 & 6.78 \\
\hline 11 & 0 & 0 & 9.57 & 9.77 \\
\hline 12 & 0 & 0 & 10.14 & 9.77 \\
\hline 13 & -1 & -1 & 5.10 & 4.73 \\
\hline
\end{tabular}

The significance of the model and its second-order Equation (2), derived from the multiple regression analysis of the data, was tested by analysis of variance (ANOVA) (Table 3) and a $p$-value lower than 0.05 was considered significant in the analysis.

Table 3. Analysis of variance for biomass production using coded values and regression equation.

\begin{tabular}{cccccc}
\hline Source & DF $^{\mathbf{a}}$ & Adj SS $^{\mathbf{b}}$ & Adj $^{\text {MS }} \mathbf{c}^{\mathbf{c}}$ & F-Value & $\boldsymbol{p}^{\text {-Value }}$ \\
\hline Model & 5 & 16.45 & 3.29 & 23.35 & 0.003 \\
Glucose $\left(\mathrm{X}_{1}\right)$ & 1 & 4.59 & 4.59 & 32.60 & 0.005 \\
SBY $\left(\mathrm{X}_{2}\right)$ & 1 & 1.27 & 1.27 & 9.07 & 0.011 \\
Linear & 2 & 5.87 & 2.93 & 20.84 & 0.001 \\
Square & 2 & 10.52 & 5.26 & 37.35 & 0.000 \\
$\mathrm{X}_{1}^{*} \mathrm{X}_{1}$ & 1 & 3.22 & 3.22 & 22.91 & 0.004 \\
$\mathrm{X}_{2}{ }^{*} \mathrm{X}_{2}$ & 1 & 3.28 & 3.28 & 23.34 & 0.002 \\
$\mathrm{X}_{1}{ }^{*} \mathrm{X}_{2}$ & 1 & 0.05 & 0.05 & 0.36 & 0.868 \\
Error & 7 & 0.98 & 0.14 & & \\
Lack of Fit & 3 & 0.87 & 0.29 & 9.19 & 0.129 \\
Pure Error & 4 & 0.11 & 0.02 & & \\
Total & 12 & 17.4376 & & & \\
\hline
\end{tabular}

$\mathrm{R}^{2}=97.68$ (a DF, degree of freedom; ${ }^{\mathrm{b}} \mathrm{SS}$, sum of squares; ${ }^{\mathrm{c}} \mathrm{MS}$, mean squares; F, probability of distribution; $p$, probability)

The model fit is also expressed with coefficient of determination $\left(R^{2}\right)$, which was 0.9768 , indicating that $97.68 \%$ of the variability in the $\mathrm{Y}$ (response) could be explained by the model. The $p$-value of the model was $(p<0.005)$, which implied that the model was significant; furthermore, the lack of fit is non-significant $(p>0.05)$, proving the validity of the model. Moreover, the predicted value observed from the model was not significantly 
different from the experimental value. The regression equation obtained from the model has been shown in Equation (1):

$$
\begin{aligned}
& \text { Biomass dry weight }\left(\mathrm{gL}^{-1}\right)=4.736+0.194 \mathrm{Glu}+1.816 \mathrm{SBY}- \\
& 0.00384 \mathrm{Glu} * \mathrm{Glu}-0.2433 \mathrm{SBY} * \mathrm{SBY}+0.00067 \mathrm{Glu} * \mathrm{SBY}
\end{aligned}
$$

Based on ANOVA analysis, both factors showed significant impact on the growth of A. mangrovei. The most significant factor was glucose $(p=0.003)$ followed by SBY $(p=0.011)$.

In the run $\mathrm{n} .13$, without the addiction of glucose or SBY, the biomass obtained was $5.1 \mathrm{~g} \mathrm{~L}^{-1}$, while the highest DW value was obtained in run $2\left(10.24 \mathrm{~g} \mathrm{~L}^{-1}\right)$ with a combination of $2.5 \mathrm{~g} \mathrm{~L}^{-1}$ of SBY and $30 \mathrm{~g} \mathrm{~L}^{-1}$ of glucose. With supplementation of SBY and organic carbon, the biomass productivity was doubled. To better understand the RSM results, a 3-D surface plot and a contour plot were elaborated and reported in Figure 4.
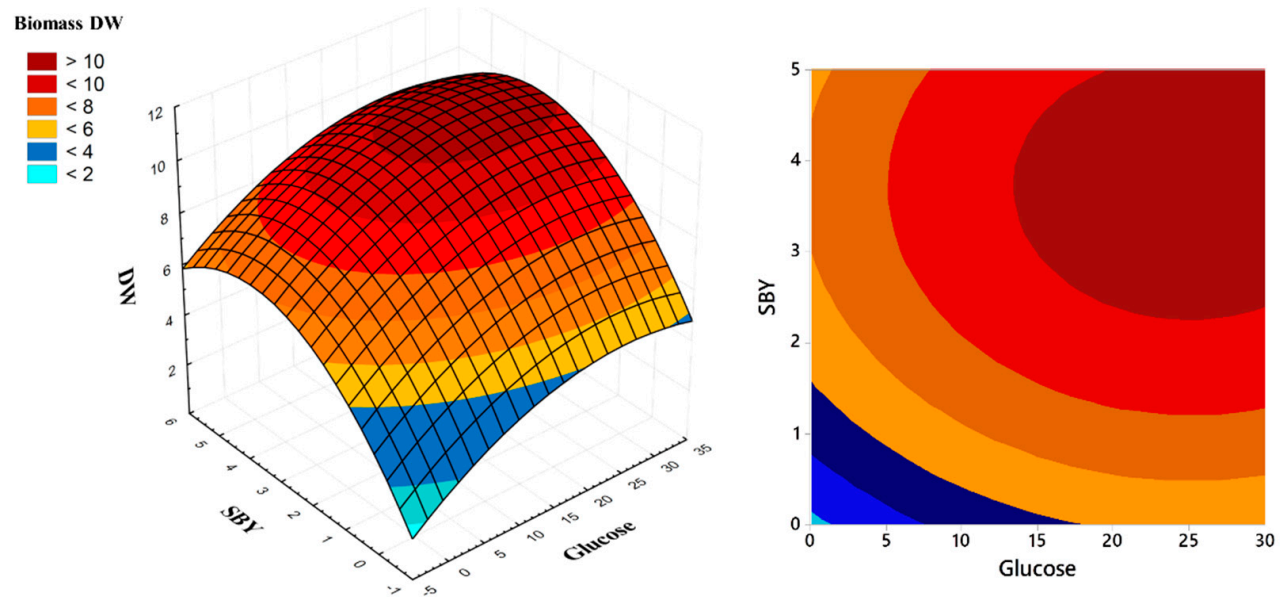

Figure 4. Surface (left) and contour plot (right) of RSM-CCD elaborated for A. mangrovei cultivated in MSW medium supplemented with spent brewery yeast and glucose.

From the figure it is possible to observe that a glucose supplementation higher than $15 \mathrm{~g} \mathrm{~L}^{-1}$ and $3.26 \mathrm{~g} \mathrm{~L}^{-1}$ of SBY are useless in terms of biomass productivity. In fact, the biomass DW seems to be stable at $10 \mathrm{~g} \mathrm{~L}^{-1}$ after these values. The optimal concentrations of factors extrapolated from regression equations are: $15.34 \mathrm{~g} \mathrm{~L}^{-1}$ of glucose and $3.22 \mathrm{~g} \mathrm{~L}^{-1}$ of SBY to supplement at MSW medium to obtain a biomass higher than $10 \mathrm{~g} \mathrm{~L}^{-1}$.

For the optimal concentration of nitrogen, other works reported an optimal concentration of YE at 10-15 $\mathrm{g} \mathrm{L}^{-1}$ for Aurantiochytrium mangrovei [29,30], while for this work it is $3.26 \mathrm{~g} \mathrm{~L}^{-1}$, suggesting the utilization of hydrolyzed proteins and FAN present in MSW by the microalga as $\mathrm{N}$ source.

\subsection{Model Confirmation and Characterization of Biomass Obtained with New MSW Optimized Medium}

Once the optimal formulation of new MSW media was established, we confirmed the predicted biomass of the model cultivating A. mangrovei with a supplementation of $15.34 \mathrm{~g} \mathrm{~L}^{-1}$ of glucose and $3.22 \mathrm{~g} \mathrm{~L}^{-1}$ of SBY in MSW media. Moreover, we evaluated the lipid content and the nutrient consumption of the new medium. The results are reported in Table 4. 
Table 4. Comparison of biomass dry weight, lipid content, FAN and sugar consumption of A. mangrovei between standard media and new MSW medium optimized through CCD.

\begin{tabular}{ccc}
\hline Parameter & Control & MSW Optimized Media \\
\hline Biomass DW $\left(\mathrm{g} \mathrm{L}^{-1}\right)$ & $9.44 \pm 0.12$ & $10.07 \pm 0.23$ \\
Biomass productivity $\left(\mathrm{g} \mathrm{L}^{-1}\right.$ day $\left.^{-1}\right)$ & $3.14 \pm 0.06$ & $3.35 \pm 0.08$ \\
Total lipids (\%DW) & $41.1 \pm 1.2$ & $38.9 \pm 0.88$ \\
FAN consumption (\%) & 80.06 & 87.24 \\
Sugar consumption (\%) & 92.61 & 94.59 \\
\hline
\end{tabular}

All values are expressed an mean $(n=3) \pm \mathrm{SD}$.

The biomass obtained was in line with the prediction of the CCD model. No significant differences were observed with the standard media in terms of biomass and lipid productivity. The FAN depletion of new MSW media was higher than the control, while the sugar consumption was very similar. This proves the optimal utilization of nutrients present in MSW media by A. mangrovei.

To better understand the differences between the samples, the fatty acids profile was analyzed and reported in Figure 5.

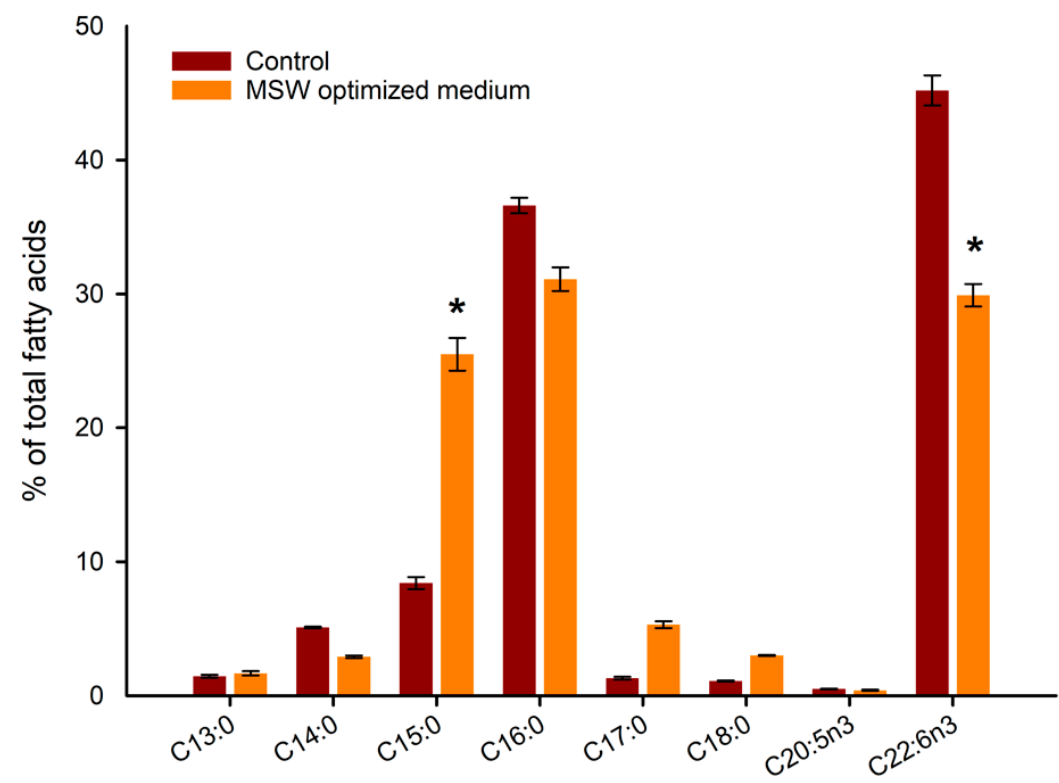

Figure 5. Fatty acids profile of extracted lipid from new MSW optimized media and standard media. $\left.{ }^{*}\right)$ means a significant difference $(p<0.05)$ with the control.

Significant differences were observed in the fatty acids profile of MSW optimized media with the relative control in standard conditions. The DHA percentage of MSW medium was significantly lower than the control ( $30.6 \%$ vs. $45 \%$ respectively). This difference could be explained by the nutrient difference between the control and the new medium with different $\mathrm{C} / \mathrm{N}$ ratios. It has been reported that fatty acids yields decrease when the carbon source is completely depleted, forcing the cells to consume their own reserves of lipids [31]. In fact, in the work of Wang et al. [32], $70 \mathrm{~g} / \mathrm{L}$ of glucose were added to tofu whey wastewater to provide an extra carbon source in order to enhance lipid accumulation of Schizochytrium sp. S31. Supplementation of extra glucose to a food waste medium is also reported in another study with Aurantiochytrium sp. KRS101. In that work, the lipids and biomass productivity were enhanced after glucose supplementation [33]. In our case, the focus was not the optimization of DHA yield but the development of a new sustainable medium for $A$. mangrovei cultivation using dairy and brewery waste. Nevertheless, the DHA percentage registered with MSW media was higher than that reported in the literature of Aurantiochytrium grown on food waste [32] and in line with another medium based on orange peel extract [33] and on food waste hydrolysate [34]. 
The content of pentadecanoic acid (C15:0) is also worthy of mention because the percentage observed in MSW medium is significantly higher than the control. In fact, $25.5 \%$ of C15 has been observed in the new medium. Odd-carbon fatty acids have been used for anaplerotic therapy for Alzheimer's disease, diabetes, cancer and cardiac disorder $[35,36]$ and represents another high added value molecule. The concentration of C15 found in our study is higher than another work conducted on Aurantiochytrium sp. SA-96 [36], where the authors studied the influence of medium components on the production of C15. In fact, the authors found that adding soy milk to the culture medium increased the production of C:15. This could be a similar case as our study.

To further define the high added value compounds obtainable from $A$. mangrovei biomass, we evaluated the carotenoids from the biomass cultivated in standard condition, with MSW optimized medium and with MSW medium at higher luminosity (Table 5).

Table 5. Table of quantification of carotenoid in A. mangrovei by HPLC-MS. (Data are given as $\mu \mathrm{g} / \mathrm{g}$ DW).

\begin{tabular}{ccccc}
\hline Sample & $\beta$-Carotene & Canthaxanthin & Astaxanthin & Violaxanthin \\
\hline Control & $0.34 \pm 0.06^{\mathrm{a}}$ & $0.62 \pm 0.05^{\mathrm{b}}$ & Trace & n.d. \\
MSW media & $2.93 \pm 0.05^{\mathrm{b}}$ & $0.29 \pm 0.04^{\mathrm{a}}$ & Trace & n.d. \\
MSW media + light & $1.85 \pm 0.02^{\mathrm{c}}$ & $0.27 \pm 0.01^{\mathrm{a}}$ & $0.28 \pm 0.01$ & $3.23 \pm 0.08$ \\
\hline Values are means + SD $(n=3) ;$ d $^{2}$ & &
\end{tabular}

Values are means \pm SD $(n=3) ;$ n.d. = not detected.

The control showed a low amount of carotenoids when compared to the other samples. Thraustochytrids are known to synthesize different carotenoids including $\beta$-carotene, astaxanthin, zeaxanthin, cantaxanthin, phoenicoxanthin and echinenone [37]. In our case, the only carotenoids found in $A$. mangrovei cultivated with standard medium are $\beta$-carotene and canthaxanthin. For the biomass obtained with MSW media instead, we found a higher content of $\beta$-carotene. This difference could be explained by the different composition of the medium, and by the presence of a different saline content that could stress the microorganism, stimulating the pigment production. Moreover, we cultivated $A$. mangrovei in MSW medium with an exposure of high luminosity during cultivation with a light intensity of $200 \mu \mathrm{mol}$ photons $\mathrm{m}^{-2} \mathrm{~s}^{-1}$ in an attempt to enhance the pigment productivity. Astaxanthin and violaxanthin were detected in that condition, increasing the high added value of the biomass obtained with food waste. In fact, biosynthetic production of carotenoids and pigment from aquatic protists are influenced by several factors, such as light exposition, saline stress and nutrient composition [38]. In scientific literature the carotenoid profile of Aurantiochytrium mangrovei is not well described, however the carotenoids found were lower with respect to Aurantiochytrium sp. SK4 [39], but in line with Aurantiochytrium limacinum ATCC MYA-1381 [40].

\subsection{Economic Considerations}

The utilization of an organic substrate and a nitrogen source are one of the main costs of heterotrophic cultivation. The utilization of pure chemicals such as glucose and yeast extract are not economically feasible for large scale productions of thraustochytrids [41]. Moreover, in order to compete with DHA from fish oil, many companies are focusing on the research of low cost nutrients to use for their fermentation processes. Therefore, the nutrient recovery from food waste and by-product is an important step to achieve. The most expensive carbon source is glucose. In 2010 its cost in the international market reached \$500/ton [42], accounting for 23-34\% of total production cost for heterotrophic cultivations [33]. However, the main issue for nutrient cost of heterotrophic protists is the nitrogen source, which is more expensive than organic carbon. In fact, the cost of YE in 2010 was assessed to be around 9.2 \$/Kg (9200 \$/ton) [43].

A recent study reported that for production of DHA oil from Schizochytrium sp., it is possible to reduce the nutrient media cost of $>70 \%$ using nitrogen from tofu wastewater [32]. In our case, the nitrogen source is completely replaced by the nutrients present in MSW and SBY, with only a small supplementation of glucose. Moreover, the glucose supplementation 
could be also replaced by other cheap organic carbon sources from food waste, as reported in our previous study [10].

With the process proposed in this study, the nutrient cost could be significantly cut. Also, the artificial seawater of the standard media has been completely replaced by MSW media, which results in a reduction in the cost of artificial seawater and mineral salts. Further studies are required to understand the economic benefit of using these food processing by-products in substitution of the standard medium, most of all a techno-economic assessment of the whole process.

\section{Materials and Methods}

\subsection{Food Waste Samples and Chemical Characterization}

MSW samples were gently provided by a mozzarella cheese factory (Capurso Azienda Casearia srl, Gioia del Colle, Bari, Italy) which concentrates the MSW using reverse osmosis in order to reduce the volume to be sent to wastewater treatment plant.

The concentrated MSW samples were taken from the accumulation tanks of the factory, aliquoted and immediately frozen at $-20{ }^{\circ} \mathrm{C}$ to prevent any fermentation. Prior any analysis, the samples were filtered to remove big solid particulates that could interfere to the biomass growth. Pre-treatment of MSW consisted in a first neutralization from $\mathrm{pH}$ 3.5 to 7.0 using $\mathrm{NaOH} 5 \mathrm{M}$. After that, the samples were heated to $80{ }^{\circ} \mathrm{C}$ for $10 \mathrm{~min}$ and then centrifuged at $14,000 \times g$ for $7 \mathrm{~min}$ to remove the precipitate [8]. The supernatant was collected and sterilized at $121^{\circ} \mathrm{C}$ for $15 \mathrm{~min}$.

Spent brewery yeast (SBY) was obtained from an artisanal brewery factory. SBY was aliquoted and frozen at $-20{ }^{\circ} \mathrm{C}$. Hydrolysis of SBY was obtained by the standard autolysis method reported by Jacob et al. [44]. Autolysis in the distilled water reported was best in terms of cell growth and economic feasibility. After autolysis, the DW of SBY lysate was $47.5 \mathrm{~g} \mathrm{~L}^{-1}$ and $\mathrm{TN}$ was $4.51 \mathrm{~g} \mathrm{~L}^{-1}$.

\subsection{Organism and Cultivation}

Aurantiochytrium mangrovei (RCC893) was obtained from the Roscoff algae collection (Roscoff, France). A stock culture of an axenic microalga strain was maintained routinely by regular sub-culturing at 2-week intervals on both liquid and agar slants of YEP Medium obtained from half-strength artificial seawater $\left(17.5 \mathrm{~g} \mathrm{~L}^{-1}\right.$ of sea salts) with $30 \mathrm{~g} \mathrm{~L}^{-1}$ of glucose, adjusted at $\mathrm{pH}$ 6.5. The nitrogen $(\mathrm{N})$ source was peptone $\left(2 \mathrm{~g} \mathrm{~L}^{-1}\right)$ and yeast extract $\left(5 \mathrm{~g} \mathrm{~L}^{-1}\right)$. The algae were cultivated in the presence of light (light intensity, $50 \mu \mathrm{mol}$ photons $\mathrm{m}^{-2} \mathrm{~s}^{-1}$ ) at temperature of $25 \pm 2{ }^{\circ} \mathrm{C}$. Culture agitation was provided by means of an orbital shaker at $200 \mathrm{rpm}$.

\subsection{Experimental Design}

The experimental design consisted of four steps: (1) a screening test to evaluate the behavior of the protist in the presence of various carbon sources and with various enzymatic hydrolysis of MSW; (2) evaluation of different concentrations of MSW as basal medium and screening for SBY as the only nitrogen source; (3) a central composite design (CCD) for the determination of the optimal supplementation of SBY and glucose to MSW medium; and (4) characterization of the biomass obtained in terms of high added value products (lipids and carotenoids).

\section{Screening Tests}

For the screening test, three trials were conducted: the first for the evaluation of A. mangrovei growth under different types of carbon source; the second to evaluate the growth of $A$. mangrovei in the presence of different concentrations of MSW; the third to evaluate the utilization of SBY as main nitrogen source for $A$. mangrovei.

For the first screening, the carbon sources used were glucose, galactose, lactose and lactic acid, adding the same amount of carbon (in $\mathrm{g} \mathrm{L}^{-1}$ ) of the control with glucose. The second screening was conducted using four concentrations of MSW: 25, 50, 75 and 100\% 
(dilution $v / v$ ). The dilution was obtained using distilled water without the addition of any other nutrient. The third screening was made using SBY as the only nitrogen source in substitution of standard yeast extract. The salinity of all samples was set at $1.75 \%(v / v)$ using commercial Aquaforest巴sea salts. A working volume of $300 \mathrm{~mL}$ was placed in a $500 \mathrm{~mL}$ Erlenmeyer flask for each concentration. A. mangrovei was inoculated into each flask to reach an initial concentration of $400 \mathrm{mg} \mathrm{L}^{-1}$ of DW. The experiment was carried out at $28^{\circ} \mathrm{C}$ and the mixing was provided through an air bubbling system equipped with a filter of $0.22 \mu \mathrm{m}$ in order to prevent any contamination and to provide oxygenation to the culture.

\subsection{Hydrolysis of Dairy Wastewater}

Enzymatic hydrolyses of MSW were carried out using the method proposed by Bikash et al. [45] with minor modifications. A sequential hydrolysis has been conducted in order to obtain a hydrolysate without lactose and high molecular weight proteins. The protocol used was the following: $300 \mathrm{~mL}$ of MSW was heated at $85^{\circ} \mathrm{C}$ for $1 \mathrm{~h}$ in a water bath in order to stabilize the product. After that, the samples were transferred on an orbital shaker set at $37^{\circ} \mathrm{C}$ and a food grade lactase was added to the bottles $\left(186 \mathrm{mg} \mathrm{L}^{-1}\right)$. At the end, the samples were heated at $90^{\circ} \mathrm{C}$ for $5 \mathrm{~min}$ to inactivate the lactase.

After this first step of hydrolysis, we began the proteolysis phase. The bottles were placed on an orbital shaker at $50^{\circ} \mathrm{C}, 150 \mathrm{rpm}$ and $12.5 \mathrm{~mL}$ of protease from Aspergillus oryzae (Merck, Rome, Italy) were added, corresponding to about 16,000 LAPU aminopeptidase units per liter of MSW. Proteolysis was carried out for $3 \mathrm{~h}$. After this period, the enzyme was inactivated at $85^{\circ} \mathrm{C}$ for $3 \mathrm{~h}$. The samples obtained were frozen to prevent any fermentation.

\subsection{Response Surface Analysis and Formulation of Optimized Media}

The new media obtained from hydrolysed MSW was optimized using response surface methodology (RSM). RSM is one of the most effective method for the optimization of the fermentation process [46]. This method was applied to formulate the optimal combination of glucose (carbon content) and spent brewery yeast (nitrogen source) to supplement the new hydrolysed MSW medium in order to enhance the biomass production. SBY supplementation was expressed as $\mathrm{g} \mathrm{L}^{-1}$ of lysate DW.

The RSM has been done by constructing a three level full factorial central composite design (CCD). The optimization consisted of 13 runs conducted in two blocks with 4 cubic points (or factorial points), 4 axial points (or star points) and 3 center points for each block.

The mathematical relationship of the response $(Y)$ to the significant independent variables $X_{1}$ and $X_{2}$ is given by the following quadratic polynomial Equation (2):

$$
Y=\beta_{0}+\sum_{i=1}^{n} \beta_{i} X_{i}+\sum_{i=1}^{n} \beta_{i i} X_{i}^{2}+\sum_{i=1}^{n} \beta_{i j} X_{i} X_{j}
$$

where $Y$ is the predicted response; $X_{i}$ and $X_{j}$ are the coded values; $\beta_{0}$ the independent coefficient; $\beta_{i, j}$ is the linear coefficient associated to each independent factor $\left(X_{i, j}\right)$ and $\beta_{i j}$ and $\beta_{\mathrm{ii}}$ are the coefficient for interaction and quadratic effects, respectively [47].

The optimal condition extrapolated from the model was also confirmed by cultivating A. mangrovei with the new nutrients parameters, and compared with the prediction of the model.

\subsection{Analytical Methods}

\subsubsection{Measurement of Dry Cell Weight}

Every $24 \mathrm{~h}, 10 \mathrm{~mL}$ of culture volume were taken and transferred in weighted dry tubes, then centrifuged at $5000 \times g$ for $10 \mathrm{~min}$. The supernatants were discarded, the pellets were washed twice with phosphate buffered saline (PBS) and dried overnight in an oven at $105^{\circ} \mathrm{C}$ to obtain the dry cell weight (DW) [11]. 


\subsubsection{Chemical Characterization of Food Waste}

For the evaluation of the chemical-physical composition, a different type of analysis has been performed using standard methods to obtain dry weight, ash, salt content, moisture, $\mathrm{pH}$ and protein content [17]. The ash content was determined gravimetrically until reaching a constant weight in a muffle furnace at $550{ }^{\circ} \mathrm{C}$. The protein content was evaluated by the Bradford assay [48] using bovine serum albumin (BSA) as the standard (MilliporeSigma, Burlington, MA, USA) and a Shimadzu UV-1700 spectrophotometer (Kyoto, Japan) for the reading of the absorbance.

The determination of reducing sugars was obtained with the dinitrosalicylic assay (DNS) [49], and the lactose has been determined spectrophotometrically following the AOAC method 2006.06 [50]. The $\mathrm{pH}$ value was detected using a $\mathrm{pH}$ meter (Mettler Toledo, Switzerland). The salinity content was evaluated with a hand refractometer. $\mathrm{The}^{\mathrm{Mg}}{ }^{2+}$, $\mathrm{Cl}^{-}$and $\mathrm{Ca}^{2+}$ content were established following ISO standards [51]. FAN content was estimated with the ninhydrin reaction method described by [52].

\subsubsection{Lipid Extraction and Fatty Acid Methyl Esters (FAMEs)}

The total amount of lipids were extracted according to a method previously established by Cha et al. [53], with minor modifications. $0.1 \mathrm{~g}$ of a powdered microalga sample was extracted with $3.33 \mathrm{~mL}$ of concentrated $\mathrm{HCl}(37 \%)$. The mixture was shaken using a vortex for $2 \mathrm{~min}$ and boiled twice at $100{ }^{\circ} \mathrm{C}$ for $20 \mathrm{~min}$ to induce cell disruption. The tubes were cooled at room temperature. Lastly, the lipid fraction was extracted three times: once with $4 \mathrm{~mL}$ of hexane and twice with $2.5 \mathrm{~mL}$ of hexane. The fatty acid methyl esters (FAMEs) were prepared from the total amount of previously obtained lipids by a transmethylation reaction utilizing a methodology previously described with certain modifications [54]. $20 \mathrm{mg}$ of lipid extract was mixed with $50 \mu \mathrm{L} 2 \mathrm{~N} \mathrm{KOH}$ in methanol, $500 \mu \mathrm{L}$ of n-hexane and $500 \mu \mathrm{L}$ of methylnonadecanoate (Sigma, St. Louis, MO, USA) as internal standard ( $1 \mathrm{mg} / \mathrm{mL})$. The mixture was vortexed for two min. The upper layer supernatant (FAME extract) was collected and injected into a gas chromatography-mass spectrometer (GC-MS). Microalgal extracts were analyzed according to the method conditions previously described by Conde et al. [55]. The analyses were carried out by using an Agilent 7890A gas chromatograph coupled to a Waters QUATTRO microTM mass spectrometer detector. The separation was achieved on a capillary column DB-5MS (30 $\mathrm{m} \times 0.25 \mathrm{~mm}$; f.t. $0.25 \mu \mathrm{m})$ purchased from Agilent Technologies (J\&W Scientific, Folsom, CA, USA). The oven temperature was $58{ }^{\circ} \mathrm{C}$ for $2 \mathrm{~min}, 25{ }^{\circ} \mathrm{C} \min ^{-1}$ to $160{ }^{\circ} \mathrm{C}, 2{ }^{\circ} \mathrm{C} \min ^{-1}$ to $210{ }^{\circ} \mathrm{C}, 30{ }^{\circ} \mathrm{C} \mathrm{min}$ m $^{-1}$ to $225{ }^{\circ} \mathrm{C}$ (held for $20 \mathrm{~min}$ ). The MS detector operates with an ionization energy of $70 \mathrm{eV}$ and a scanning range of $\mathrm{m} / \mathrm{z} 50-550 \mathrm{~m} / \mathrm{z}$. The conditions were helium as carrier gas at $1.4 \mathrm{~mL} \mathrm{~min}^{-1}$, the inlet temperature was $220^{\circ} \mathrm{C}$, the detector temperature was $230{ }^{\circ} \mathrm{C}, 2 \mu \mathrm{L}$ of injection volume (splitless). Data were analyzed using MassLynx version 4.1 (Waters, San Jose, CA, USA).

\subsubsection{Determination of Carotenoids in Microalgal Extracts by HPLC/MS Analysis}

The extraction was obtained by using an ultrasonic bath (Bandelin, Sonorex, RK52, Berlin, Germany), which operates at a frequency of $35 \mathrm{kHz}$ according to the protocol described previously by Castro-Puyana et al. 2013 [56] with some modifications. Briefly, $10 \mathrm{mg}$ of a sample of microalgal was added to $1.5 \mathrm{~mL}$ of ethanol containing $0.1 \%(w / v)$ of butylated hydroxytoluene. The mixture was centrifuged for $10 \mathrm{~min}$ at $10,000 \times \mathrm{g} \mathrm{rpm}\left(4^{\circ} \mathrm{C}\right)$. The extracts were collected and filtered through $0.2 \mu \mathrm{m}$ nylon syringe filters and stored at $-18^{\circ} \mathrm{C}$ until the analyses.

Microalgal extracts were analyzed by UPLC Acquity coupled XEVO-TQ-S Triple quadrupole mass spectrometry (Waters Corporation, Milford, MA, USA). Carotenoids were separated on an YMC-C30 reversed-phase column $(250 \times 4.6 \mathrm{~mm} .3 \mu \mathrm{m})$. The mobile phase consisted of methanol with $5 \%$ water and $0.1 \%$ formic acid as mobile phase $\mathrm{A}$ and methyl tert-butyl ether as mobile phase B. The conditions of the solvent gradient were $60 \% \mathrm{~A}$ to $0 \% \mathrm{~A}$ in $30 \mathrm{~min}$ with a flow rate of $1 \mathrm{~mL} \mathrm{~min}{ }^{-1}$. Analysis parameters were arranged using a positive-ion mode. The parameters of multiple reaction monitoring 
MRM transitions for all the standards are listed in supplementary material (Table S1). Additional mass spectrometric parameters were as follows: Source temperature was $150{ }^{\circ} \mathrm{C}$, the desolvation temperature was $500{ }^{\circ} \mathrm{C}$, cone gas flow $150^{\circ} \mathrm{C}$, the source offset was $30 \mathrm{~V}$, the desolvation gas flow was $1000 \mathrm{~L} / \mathrm{h}$, the collision gas flow was $0.15 \mathrm{~mL} \mathrm{~min}^{-1}$, and the collision gas was argon. The data was acquired using MassLynx version 4.1 (Waters, San Jose, CA, USA). Carotenoids were quantified by standards of violaxanthin, astaxanthin, canthaxanthin and $\beta$-carotene. The calibration curves were prepared from the limit of quantification (LOQ) to 500-625 $\mathrm{mg} \mathrm{L}^{-1}$. All calibration curves revealed a good linearity among different concentrations, and the determination coefficients were higher than 0.9918 in all cases. The method used for analysis showed a limit of detection (LOD) within the range $0.02-2.06 \mu \mathrm{g} \mathrm{L}^{-1}$ and the LOQ was within $0.08-6.85 \mu \mathrm{g} \mathrm{L}^{-1}$ (Table S2).

\subsection{Statistical Analysis}

All the analyses were carried out in triplicate, and average values with standard deviation were reported. One-way ANOVA was applied using raw data to test for significant differences among the samples (significance level was always set at $p<0.05$ ). The Tukey's test was used for post-hoc analysis when there were significant differences among the samples. The data were analyzed using IBMC SPSS@ Statistics software Ver. 23 (SPSS, Inc., Chicago, IL, USA). RSM analysis was carried out using Statistica 7.0 package (StatSoft, Tulsa, OK, USA).

\section{Conclusions}

The combination of wastewater from mozzarella manufacturing and brewery waste showed a promising alternative for a more sustainable Aurantiochytrium mangrovei cultivation. Pre-treatment of MSW is mandatory to achieve an optimal biomass concentration and lipid production. Enzymatic hydrolyses achieved good growth performances in terms of biomass produced. However, a supplementation of nitrogen from spent brewery yeast and glucose is required to boost the growth of $A$. mangrovei using MSW.

The optimization with RSM leads to a biomass DW of $10.14 \mathrm{~g} \mathrm{~L}^{-1}$ with $38.9 \%$ of lipids and $29.8 \%$ of DHA on total FAME. The results are comparable to the relative growth with standard media. These findings suggest that hydrolyzed MSW with SBY can be used in new biotechnological processes in order to reduce nutrient costs for production of biomass that is rich in DHA oil.

Supplementary Materials: The following supporting information can be downloaded at https: / / www.mdpi.com/article/10.3390/md20010039/s1, Table S1: Parameters for The MRM transitions, Table S2: Calibration curves of standards for the determination of carotenoid in microalgae.

Author Contributions: Conceptualization, G.L.R. and A.L.L.; methodology, A.L.L., P.D.P., A.S., V.V. and B.M-G.; software, G.L.R.; validation, A.L.L., R.S., P.D.P., P.M. and V.V.; formal analysis, G.L.R., A.S., V.V., B.M-G., M.B., M.O. and A.S.; investigation, G.L.R., A.L.L., B.M.-G. and V.V.; resources, P.M.; data curation, G.L.R., M.O., B.M.-G. and V.V.; writing G.L.R., A.L.L. and B.M,-G.; writing-review and editing, A.L.L., V.V., A.S., M.O., R.S. and P.M.; visualization, G.L.R.; supervision, A.L.L. and R.S.; project administration, P.M.; funding acquisition, P.M. All authors have read and agreed to the published version of the manuscript.

Funding: This research was funded by the SUSPUFA project, ID 145, as part of the ERA-Net SUSFOOD2, with funding provided by national and regional sources (Ministero dell'Istruzione dell'Università e della Ricerca, MIUR and Spanish Ministry of Science, Education and Universities/Spanish State Research Agency-PCI2018-093178) and was co-funded by the European Union's Horizon 2020 research and innovation programme.

Institutional Review Board Statement: Not applicable.

Informed Consent Statement: Not applicable.

Data Availability Statement: Not applicable. 
Acknowledgments: Vito Verardo thanks the MINECO for his "Ramon y Cajal" contract (RYC-201518795).

Conflicts of Interest: The authors declare no conflict of interest.

\section{References}

1. Gharami, K.; Das, M.; Das, S. Essential role of docosahexaenoic acid towards development of a smarter brain. Neurochem. Int. 2015, 89, 51-62. [CrossRef]

2. Birch, E.E.; Garfield, S.; Castañeda, Y.; Hughbanks-Wheaton, D.; Uauy, R.; Hoffman, D. Visual acuity and cognitive outcomes at 4 years of age in a double-blind, randomized trial of long-chain polyunsaturated fatty acid-supplemented infant formula. Early Hum. Dev. 2007, 83, 279-284. [CrossRef] [PubMed]

3. Shahidi, F.; Ambigaipalan, P. Omega-3 Polyunsaturated Fatty Acids and Their Health Benefits. Annu. Rev. Food Sci. Technol. 2018, 9, 345-381. [CrossRef] [PubMed]

4. Chen, W.; Zhou, P.; Zhu, Y.; Xie, C.; Ma, L.; Wang, X.; Bao, Z.; Yu, L. Improvement in the docosahexaenoic acid production of Schizochytrium sp. S056 by replacement of sea salt. Bioprocess Biosyst. Eng. 2016, 39, 315-321. [CrossRef] [PubMed]

5. Graham, I.A.; Larson, T.; Napier, J.A. Rational metabolic engineering of transgenic plants for biosynthesis of omega-3 polyunsaturates. Curr. Opin. Biotechnol. 2007, 18, 142-147. [CrossRef]

6. Lewis, T.E.; Nichols, P.D.; McMeekin, T.A. The Biotechnological Potential of Thraustochytrids. Mar. Biotechnol. 1999, 1, 580-587. [CrossRef] [PubMed]

7. Gao, M.; Song, X.; Feng, Y.; Li, W.; Cui, Q. Isolation and characterization of Aurantiochytrium species: High docosahexaenoic acid (DHA) production by the newly isolated microalga, Aurantiochytrium sp. SD116. J. Oleo Sci. 2013, 62, 143-151. [CrossRef]

8. Humhal, T.; Kastanek, P.; Jezkova, Z.; Cadkova, A.; Kohoutkova, J.; Branyik, T. Use of saline waste water from demineralization of cheese whey for cultivation of Schizochytrium limacinum PA-968 and Japonochytrium marinum AN-4. Bioprocess Biosyst. Eng. 2017, 40, 395-402. [CrossRef]

9. Ende, S.S.W.; Noke, A. Heterotrophic microalgae production on food waste and by-products. J. Appl. Phycol. 2019, 31, 1565-1571. [CrossRef]

10. Russo, G.L.; Langellotti, A.L.; Blasco, T.; Oliviero, M.; Sacchi, R.; Masi, P. Production of Omega-3 Oil by Aurantiochytrium mangrovei Using Spent Osmotic Solution from Candied Fruit Industry as Sole Organic Carbon Source. Processes 2021, 9, 1834. [CrossRef]

11. Ryu, B.-G.; Kim, K.; Kim, J.; Han, J.-I.; Yang, J.-W. Use of organic waste from the brewery industry for high-density cultivation of the docosahexaenoic acid-rich microalga, Aurantiochytrium sp. KRS101. Bioresour. Technol. 2013, 129, 351-359. [CrossRef]

12. Castrica, M.; Ventura, V.; Panseri, S.; Ferrazzi, G.; Tedesco, D.; Balzaretti, C.M. The sustainability of urban food systems: The case of mozzarella production in the city of Milan. Sustainability 2020, 12, 682. [CrossRef]

13. Kasmi, M. Biological Processes as Promoting Way for Both Treatment and Valorization of Dairy Industry Effluents. Waste Biomass Valorization 2018, 9, 195-209. [CrossRef]

14. Zotta, T.; Solieri, L.; Iacumin, L.; Picozzi, C.; Gullo, M. Valorization of cheese whey using microbial fermentations. Appl. Microbiol. Biotechnol. 2020, 104, 2749-2764. [CrossRef]

15. Yuan, X.; Liang, L.; Liu, K.; Xie, L.; Huang, L.; He, W.; Chen, Y.; Xue, T. Spent yeast as an efficient medium supplement for fucoxanthin and eicosapentaenoic acid (EPA) production by Phaeodactylum tricornutum. J. Appl. Phycol. 2020, 32, 59-69. [CrossRef]

16. Pleissner, D.; Lam, W.C.; Sun, Z.; Lin, C.S.K. Food waste as nutrient source in heterotrophic microalgae cultivation. Bioresour. Technol. 2013, 137, 139-146. [CrossRef]

17. Massa, M.; Buono, S.; Langellotti, A.L.; Martello, A.; Russo, G.L.; Troise, D.A.; Sacchi, R.; Vitaglione, P.; Fogliano, V. Biochemical composition and in vitro digestibility of Galdieria sulphuraria grown on spent cherry-brine liquid. New Biotechnol. 2019, 53, 9-15. [CrossRef] [PubMed]

18. Ratledge, C. Fatty acid biosynthesis in microorganisms being used for Single Cell Oil production. Biochimie 2004, 86, 807-815. [CrossRef] [PubMed]

19. Panesar, P.; Kennedy, J.; Gandhi, D.; Bunko, K. Bioutilisation of whey for lactic acid production. Food Chem. 2007, 105, 1-14. [CrossRef]

20. Chokshi, K.; Pancha, I.; Ghosh, A.; Mishra, S. Microalgal biomass generation by phycoremediation of dairy industry wastewater: An integrated approach towards sustainable biofuel production. Bioresour. Technol. 2016, 221, 455-460. [CrossRef]

21. Humhal, T.; Kronusová, O.; Kaštánek, P.; Potočár, T.; Kohoutková, J.; Brányik, T. Influence of nitrogen sources on growth of thraustochytrids in waste water from the demineralization of cheese whey. Czech J. Food Sci. 2019, 37, 383-390. [CrossRef]

22. Gernigon, G.; Piot, M.; Beaucher, E.; Jeantet, R.; Schuck, P. Physicochemical characterization of Mozzarella cheese wheys and stretchwaters in comparison with several other sweet wheys. J. Dairy Sci. 2009, 92, 5371-5377. [CrossRef]

23. Pahlavanyali, M.; Jalili, H.; Noroozi, M.; Moradi, Y.; Hallajisani, A. The effect of temperature and different carbon and nitrogen sources on the growth and fatty acid profile of a newly isolated microorganism Aurantiochytrium sp. strain SHY. Iran. J. Fish. Sci. 2020, 19, 3112-3126. [CrossRef]

24. Unagul, P.; Assantachai, C.; Phadungruengluij, S.; Suphantharika, M.; Verduyn, C. Properties of the docosahexaenoic acidproducer Schizochytrium mangrovei Sk-02: Effects of glucose, temperature and salinity and their interaction. Bot. Mar. 2005, 48, 387-394. [CrossRef] 
25. Ju, J.-H.; Ko, D.-J.; Heo, S.-Y.; Lee, J.-J.; Kim, Y.-M.; Lee, B.-S.; Kim, M.-S.; Kim, C.-H.; Seo, J.-W.; Oh, B.-R. Regulation of lipid accumulation using nitrogen for microalgae lipid production in Schizochytrium sp. ABC101. Renew. Energy 2020, 153, 580-587. [CrossRef]

26. Song, X.; Ma, Z.; Tan, Y.; Zhang, H.; Cui, Q. Wastewater recycling technology for fermentation in polyunsaturated fatty acid production. Bioresour. Technol. 2017, 235, 79-86. [CrossRef] [PubMed]

27. Wong, M.K.M.; Tsui, C.K.M.; Au, D.W.T.; Vrijmoed, L.L.P. Docosahexaenoic acid production and ultrastructure of the thraustochytrid Aurantiochytrium mangrovei MP2 under high glucose concentrations. Mycoscience 2008, 49, 266-270. [CrossRef]

28. Yokochi, T.; Honda, D.; Higashihara, T.; Nakahara, T. Optimization of docosahexaenoic acid production by Schizochytrium limacinum SR21. Appl. Microbiol. Biotechnol. 1998, 49, 72-76. [CrossRef]

29. Yu, X.-J.; Yu, Z.-Q.; Liu, Y.-L.; Sun, J.; Zheng, J.-Y.; Wang, Z. Utilization of High-Fructose Corn Syrup for Biomass Production Containing High Levels of Docosahexaenoic Acid by a Newly Isolated Aurantiochytrium sp. YLH70. Appl. Biochem. Biotechnol. 2015, 177, 1229-1240. [CrossRef]

30. Ju, J.-H.; Oh, B.-R.; Ryu, S.-K.; Heo, S.-Y.; Kim, S.-Y.; Hong, W.-K.; Kim, C.H.; Seo, J.-W. Production of Lipid Containing High Levels of Docosahexaenoic Acid by Cultivation of Aurantiochytrium sp. KRS101 Using Jerusalem Artichoke Extract. Biotechnol. Bioprocess Eng. 2018, 23, 726-732. [CrossRef]

31. Wu, S.-T.; Yu, S.-T.; Lin, L.-P. Effect of culture conditions on docosahexaenoic acid production by Schizochytrium sp. S31. Process Biochem. 2005, 40, 3103-3108. [CrossRef]

32. Wang, S.-K.; Wang, X.; Tian, Y.-T.; Cui, Y.-H. Nutrient recovery from tofu whey wastewater for the economical production of docosahexaenoic acid by Schizochytrium sp. S31. Sci. Total Environ. 2020, 710, 136448. [CrossRef] [PubMed]

33. Park, W.-K.; Moon, M.; Shin, S.-E.; Cho, J.M.; Suh, W.I.; Chang, Y.K.; Lee, B. Economical DHA (Docosahexaenoic acid) production from Aurantiochytrium sp. KRS101 using orange peel extract and low cost nitrogen sources. Algal Res. 2018, 29, 71-79. [CrossRef]

34. Patel, A.; Rova, U.; Christakopoulos, P.; Matsakas, L. Mining of squalene as a value-added byproduct from DHA producing marine thraustochytrid cultivated on food waste hydrolysate. Sci. Total Environ. 2020, 736, 139691. [CrossRef]

35. Des Rosiers, C.; Labarthe, F.; Lloyd, S.G.; Chatham, J.C. Cardiac anaplerosis in health and disease: Food for thought. Cardiovasc. Res. 2011, 90, 210-219. [CrossRef] [PubMed]

36. Kaya, K.; Kazama, Y.; Abe, T.; Shiraishi, F. Influence of medium components and pH on the production of odd-carbon fatty acids by Aurantiochytrium sp. SA-96. J. Appl. Phycol. 2020, 32, 1597-1606. [CrossRef]

37. Aasen, I.M.; Ertesvåg, H.; Heggeset, T.M.B.; Liu, B.; Brautaset, T.; Vadstein, O.; Ellingsen, T.E. Thraustochytrids as production organisms for docosahexaenoic acid (DHA), squalene, and carotenoids. Appl. Microbiol. Biotechnol. 2016, 100, 4309-4321. [CrossRef]

38. Galasso, C.; Corinaldesi, C.; Sansone, C. Carotenoids from Marine Organisms: Biological Functions and Industrial Applications. Antioxidants 2017, 6, 96. [CrossRef]

39. Ye, J.; Liu, M.; He, M.; Ye, Y.; Huang, J. Illustrating and Enhancing the Biosynthesis of Astaxanthin and Docosahexaenoic Acid in Aurantiochytrium sp. SK4. Mar. Drugs 2019, 17, 45. [CrossRef]

40. Kubo, Y.; Shiroi, M.; Higashine, T.; Mori, Y.; Morimoto, D.; Nakagawa, S.; Sawayama, S. Enhanced Production of Astaxanthin without Decrease of DHA Content in Aurantiochytrium limacinum by Overexpressing Multifunctional Carotenoid Synthase Gene. Appl. Biochem. Biotechnol. 2021, 193, 52-64. [CrossRef]

41. Russo, G.L.; Langellotti, A.L.; Oliviero, M.; Sacchi, R.; Masi, P. Sustainable production of food grade omega-3 oil using aquatic protists: Reliability and future horizons. New Biotechnol. 2021, 62, 32-39. [CrossRef] [PubMed]

42. Fei, Q.; Chang, H.N.; Shang, L.; Choi, J.; Kim, N.; Kang, J. The effect of volatile fatty acids as a sole carbon source on lipid accumulation by Cryptococcus albidus for biodiesel production. Bioresour. Technol. 2011, 102, 2695-2701. [CrossRef] [PubMed]

43. Maddipati, P.; Atiyeh, H.K.; Bellmer, D.D.; Huhnke, R.L. Ethanol production from syngas by Clostridium strain P11 using corn steep liquor as a nutrient replacement to yeast extract. Bioresour. Technol. 2011, 102, 6494-6501. [CrossRef] [PubMed]

44. Jacob, F.F.; Striegel, L.; Rychlik, M.; Hutzler, M.; Methner, F.-J. Spent Yeast from Brewing Processes: A Biodiverse Starting Material for Yeast Extract Production. Fermentation 2019, 5, 51. [CrossRef]

45. Ghosh, B.C.; Prasad, L.N.; Saha, N.P. Enzymatic hydrolysis of whey and its analysis. J. Food Sci. Technol. 2017, 54, 1476-1483. [CrossRef] [PubMed]

46. Park, H.; Kwak, M.; Seo, J.; Ju, J.; Heo, S.; Park, S.; Hong, W. Enhanced production of carotenoids using a Thraustochytrid microalgal strain containing high levels of docosahexaenoic acid-rich oil. Bioprocess Biosyst. Eng. 2018, 41, 1355-1370. [CrossRef] [PubMed]

47. Nazir, Y.; Shuib, S.; Kalil, M.S.; Song, Y.; Hamid, A.A. Optimization of Culture Conditions for Enhanced Growth, Lipid and Docosahexaenoic Acid (DHA) Production of Aurantiochytrium SW1 by Response Surface Methodology. Sci. Rep. 2018, 8, 8909. [CrossRef] [PubMed]

48. Bradford, M.M. A rapid and sensitive method for the quantitation of microgram quantities of protein utilizing the principle of protein-dye binding. Anal. Biochem. 1976, 72, 248-254. [CrossRef]

49. Miller, G.L. Use of Dinitrosalicylic Acid Reagent for Determination of Reducing Sugar. Anal. Chem. 1959, 31, 426-428. [CrossRef]

50. Thiex, N. Evaluation of Analytical Methods for the Determination of Moisture, Crude Protein, Crude Fat, and Crude Fiber in Distillers Dried Grains with Solubles. J. AOAC Int. 2009, 92, 61-73. [CrossRef]

51. ISO. NF EN ISO 17294-2 Water Quality_Application of Inductively Coupled Plasma Mass Spectrometry (ICP-MS)—Part 2: Determination of Selected Elements Including Uranium Isotopes; ISO: Geneva, Switzerland, 2016. 
52. Lie, S. The Ebc-Ninhydrin Method for Determination of Free Alpha Amino Nitrogen. J. Inst. Brew. 1973, 79, 37-41. [CrossRef]

53. Cha, T.S.; Chen, J.W.; Goh, E.G.; Aziz, A.; Loh, S.H. Differential regulation of fatty acid biosynthesis in two Chlorella species in response to nitrate treatments and the potential of binary blending microalgae oils for biodiesel application. Bioresour. Technol. 2011, 102, 10633-10640. [CrossRef] [PubMed]

54. Aued-Pimentel, S.; Lago, J.H.G.; Chaves, M.H.; Kumagai, E.E. Evaluation of a methylation procedure to determine cyclopropenoids fatty acids from Sterculia striata St. Hil. Et Nauds seed oil. J. Chromatogr. A 2004, 1054, 235-239. [CrossRef] [PubMed]

55. Conde, T.A.; Couto, D.; Melo, T.; Costa, M.; Silva, J.; Domingues, M.R.; Domingues, P. Polar lipidomic profile shows Chlorococcum amblystomatis as a promising source of value-added lipids. Sci. Rep. 2021, 11, 4355. [CrossRef]

56. Castro-Puyana, M.; Herrero, M.; Urreta, I.; Mendiola, J.A.; Cifuentes, A.; Ibáñez, E.; Suárez-Alvarez, S. Optimization of clean extraction methods to isolate carotenoids from the microalga Neochloris oleoabundans and subsequent chemical characterization using liquid chromatography tandem mass spectrometry. Anal. Bioanal. Chem. 2013, 405, 4607-4616. [CrossRef] [PubMed] 